\title{
AC 2009-1044: MINDING THE BIG PICTURE: USING DISCRETE EVENT PROCESS SIMULATION AS A PROBLEM SOLVING TOOL FOR STUDENTS
}

\section{Susan Scachitti, Purdue University, Calumet}

Susan Scachitti is a Professor of Industrial Engineering Technology at Purdue University

Calumet. Professor Scachitti consults and teaches in traditional areas of Industrial Engineering including Quality Management and organizational change, Six Sigma methodologies, methods engineering, Lean thinking, facility layout, process improvement, and ergonomics. Prior to working in education, she spent ten years in various engineering and supervisory roles in the telecommunications industry which focused on high volume electronics manufacturing. Her industry accomplishments included implementation of Total Quality principles including Lean Manufacturing concepts, Demand Flow Technology, and self-directed work teams.

\section{Juan Salinas, Purdue University, Calumet}

JUAN SALINAS is a Graduate Student in the Master of Science in Technology Program at Purdue University Calumet. He holds Bachelor of Science degrees in Industrial Engineering Technology and Manufacturing Engineering Technology from Purdue University Calumet. He teaches undergraduate courses in Industrial Organization and Plant Layout and Material Handling as an adjunct instructor in Purdue University Calumet's Industrial Engineering Technology Program. As a Graduate Student, he has performed research in Heat Transfer Applications Using Nanotechnology, Advance Project Management, and Implementation of RFID Technology in Industrial Environment - Inventory Control of Steel Sheets. His professional experience focuses in Facilities Design, Manufacturing and Machining Cells Re-Design, Process Simulation, and Lean Manufacturing implementation in a heavy industrial environment. He has served as officer in several positions in Purdue University Calumet Chapters of the Institute of Industrial Engineers, Society of Manufacturing Engineers, and the Society of Automotive Engineers.

\section{Deepthi Karanam, Purdue University, Calumet}

Deepthi Karanam is a graduate student in the School of Technology at Purdue University Calumet where she is pursuing a Master of Science in Technology degree. She received her Bachelor of Engineering in Electronics and Instrumentation Engineering from Birla Institute of Technology and Science, Pilani in India. She has research and industry experience in the areas of supply chain management, cost of poor quality, RFID, simulation and modeling. 


\title{
Minding the Big Picture: Using Discrete Event Process Simulation as a Problem Solving Tool for Students
}

\begin{abstract}
As competition drives organizations to practice continuous improvement efforts such as lean manufacturing, value analysis and global supply chain initiatives, experience with process simulation software (a key technological tool for process improvement) can offer an advantage to engineering technology graduates as they pursue employment opportunities.

This paper will focus on one university's efforts to incorporate real world simulation experiences into a facility design course. The instructor's real world experience with using a cost effective and user friendly simulation package to design, build and start-up a $\$ 110$ million manufacturing facility were used to develop applicable classroom exercises to achieve appropriate student learning outcomes. Exercises reflect lessons learned in real world applications to incorporate facility support efforts such as process flow optimization and staffing level determinations as well as basic layout issues. Examples of exercises with intended learning outcomes will also be included.
\end{abstract}

\section{Introduction}

Process simulation software has proven itself to be a key problem solving tool in developing value minded graduates of engineering technology programs. Whether students find employment in manufacturing, healthcare or service industries, they will all be faced with decision making and problem solving involving increasingly complex systems and rapidly changing technology. With this in mind, theoretical concepts such as queuing theory, regression analysis, takt time calculations, as well as other traditional work flow analysis and process improvement concepts become more and more difficult for students to grasp and apply within a classroom setting. Engineering technology students, specifically those focused in industrial and manufacturing engineering technology programs, need access to hands-on support tools for analyzing the effects that their localized changes are likely to have on the big picture system. Incorporating discrete event process simulation models into routine class assignments is one way of achieving this expanded skill set for students, or, as stated by Dr. Stephens, an Industrial Technology Professor, “... in an educational setting, computer simulation can be used to add a life-like dimension when difficult and abstract models are studied."(1)

Simulation is being increasingly recognized as a useful and practical technique, especially in giving a realistic view of the system under study. Different scenarios can be analyzed in order to investigate which configuration is the best to meet the objective. (2) Traditional theoretical teaching methods teach engineering technology students the basics for problem solving. When used accordingly, simulation can enhance a student's problem solving skills. For this reason, experience with discrete event process simulation software, often associated with the Industrial Engineering Technology (IET) or Manufacturing Engineering Technology (MfET) disciplines, provides graduates with a unique and marketable skill. Unfortunately, as with most engineering technology curriculum, there is often little opportunity to add an additional course dedicated to 
simulation to an already full program of study. For this reason, Purdue University Calumet (PUC) faculty initiated steps to introduce their undergraduate students to simulation during a required course that already existed in the IET curriculum, IET 310 Plant Layout and Material Handling.

\section{Simulation use and benefit in education and industry}

The uses of simulation are extensive in both education and industry as it is a flexible and easy to use tool. Its use is not just limited to one particular field as its roots are wide spread in numerous fields such as air traffic control and space systems, business process re-engineering and workflows, complex system design evaluation, computer and communication networks, computer performance and evaluation, education and training, healthcare systems, manufacturing systems, military/combat systems, satellite and wireless communication systems, service systems, supply chain management, transportation systems, aerospace, oil and gas, construction, financial modeling, parcels and parcel handling, de-bottlenecking, what-if scenarios, robotic and mechanical systems, decision and risk analysis etc. ${ }^{(3)}$ Furthermore, the types of projects within the various fields are also varied. Types of projects vary from increasing the efficiency and effectiveness of operating rooms and emergency rooms in hospitals ${ }^{(4)}$, implementing production management systems in new manufacturing firms ${ }^{(5)}$, speeding up the dispatch bay process of a manufacturing industry ${ }^{(6)}$, to making the trip of a passenger more comfortable at an airport with minimal delays. ${ }^{(7)}$

Along with the varied uses of simulation, are various types of simulation. The simulation area that is relevant to this paper is the field of discrete event process simulation. Some of the specific projects that can be attributed to this field include the following: Savsar ${ }^{(8)}{ }^{(9)}$ presented the use of discrete-event simulation for design and evaluation of a flexible manufacturing cell system and a facility layout; in the area of manufacturing flow control \& analysis, Williams et al. ${ }^{(10)}$,West et al. ${ }^{(11)}$ report the use of discrete-event simulation to investigate the dynamics of an existing system and as an aiding tool for system improvement with a better selection of additional equipment and/or better resources allocation during system design; Kibira et al. ${ }^{(12)}$ used discreteevent simulation for the design of a production line for a mechanically assembled product; Law et al. ${ }^{(13)}$ suggest that discrete event simulation can be used to evaluate operation procedures and to measure and analyze system performance. As success stories such as these are published, industries show increased interest in process simulation software as they recognize the direct relationship of its use to increase in profits and other economic benefits. For example, by using simulation, a cancer treatment center was able to increase the number of patients seen per day by $20 \%$ and the results of their Layout Scenario Analysis showed that the occupancy of their new integrated facility would allow at least a $100 \%$ increase in chair capacity ${ }^{(14)}$. With continued results such as this being published the demand for people with knowledge and experience in this field will undoubtedly continue to grow.

Instructing IET and MfET students on discrete event process simulation concepts will allow them to gain useful knowledge and experience for problem solving and project implementation before they begin their careers. It will also aid them in visualizing the bigger picture of what is happening in industry while they are still in the classroom. One study evaluated the impact of different instructional media on student retention of subject matter and found that students 
remember only $10 \%$ of what they read; $20 \%$ of what they hear; $30 \%$, if they see visuals related to what they are hearing; $50 \%$, if they watch someone do something while explaining it; but almost $90 \%$, if they do the job themselves even if only as a simulation. In other words, guided discovery through labs and computer simulations that are properly designed and implemented could revolutionize education. ${ }^{(15)}$

\section{Simulation use in an Undergraduate Facility Design Course}

The use of simulation software at PUC in the IET program began through an educational partnership (organizational training for Lean Six Sigma) with a local healthcare facility in 2005. This partnership provided the initial opportunity for PUC's Industrial Engineering Technology laboratory to be outfitted with process simulation software (ProModel). After the completion of this initial educational industry partnership, additional industry training opportunities and projects ensued along with the highlighted need for using process simulation to solve industry problems. Opportunities for faculty and students to use the process simulation software presented themselves in areas such as manufacturing, material handling and inventory management, as well as business process reengineering. After several semesters of actively engaging students with real life simulation experiences (usually during senior design projects, graduate projects or as student workers) faculty determined that they must create an opportunity within the undergraduate IET curriculum to incorporate this tool that proved to have such a diverse application for the IET discipline. After all, ABET criterion 2 states that "an engineering technology program must prepare graduates who: a) demonstrate an appropriate mastery of the

knowledge, techniques, skills and modern tools of their discipline."(16) IET faculty at PUC believe that process simulation software is one of these modern tools that should be mastered by IET students.

This prompted the faculty to question what was being taught in other IET and MfET programs in regard to simulation. A cursory internet investigation of the mention of process simulation in other ABET accredited undergraduate industrial and manufacturing engineering technology program websites reveled surprising results. Faculty at PUC assumed that they were behind the curve in terms of adding this tool to their curriculum, however, when searching the internet for signs of process simulation use in other similar ABET accredited IET and MfET programs, not even half of the university web sites noted some use of process simulation (see appendix A). When comparing the accredited IET programs to the MfET programs it can be said that a majority of IET programs noted at least one course which focused on process simulation either in brief or in detail, however this was well under one-half for the MfET programs. Of the web sites that did note some use of process simulation, in general it was found that very few universities have a dedicated undergraduate course with emphasis on particular commercial simulation packages used in industries. It appeared that most course content focused on theoretical concepts with less emphasis on actual experience with simulating the process.

In order to better prepare students for employment, the IET faculty at PUC felt that hands on simulation exercises were needed to expose students to simulation software potential. From their real world experiences it was evident that proposed solutions or scenarios could be quickly and inexpensively simulated to show a variety of possible results. Other advantages noted were that simulation protects capital and other interest from potential mistakes that new graduates will 
most likely commit as they begin their professional careers. When using simulation software, early learning mistakes are isolated to a few invested hours simulating a proposed solution. Also, simulation exercises develop a student's creativity to explore all possible solutions since simulation allows them to evaluate various possible results. In addition, when simulation is used as part of a facilities and systems design course, students can be instructed on the best methods to analyze the data that is generated from the simulation. This is a key concept to teach students in order to help them present to management the best solution to solve a problem. Management is more likely to buy-in and support a project or process improvement when results are presented well and understood by all involved. As explained by Dr. Stephens, "because its basic concepts are easily comprehended, a simulation model is often easier to justify to management and customers than most analytical and mathematical models. The actual simulation may be impressive but if the results are not presented appropriately, projects will be shot down." (1)

\section{Bringing Real World Experience into the Class Room}

When redesigning the IET 310 Facility Layout and Material Handling course to incorporate simulation techniques, faculty incorporated their real world experiences gained while in positions of leadership in industry into the class assignments. The main topics that were included focus on the following areas:

- Data collection and analysis for use in simulation models.

- The importance of graphics in simulation and project presentation.

- Use of simulation models for problem solving.

- Use of simulation models to preview changes in management policies and their effect on operations.

Logistically, to incorporate simulation experiences into an already existing course, some existing requirements had to be relinquished. It was determined that the volume of existing assignments must be minimally reduced as the existing curriculum had time and again been assessed by graduates as presenting them with true to life step-by-step tools to accomplish their objectives for facility design. The four learning objectives of the course were reviewed and it was determined that these existing learning objectives should and could be still accomplished with one additional objective added to focus on simulation:

5. Upon successful completion of this course, students will be able to demonstrate the ability to utilize computer simulation to design appropriate process flows and proactively solve process related problems.

This not only supports the ABET criterion for graduate outcomes, but also supports the program outcomes for PUC's IET program strategic plan.

The guiding principle used to develop all of the simulation model assignments was 'to strengthen the student's problem solving skills.' It was determined that the most appropriate way to accomplish this new objective was to add simplistic assignments that centered on adjusting and analyzing simulation models that were created by the faculty. To create the models, there are 
various commercial simulation packages available that range from simplistic packages such as Process Simulator in Visio to sophisticated packages such as ProModel, MedModel, ARENA and Simul8. The selection of one or more of these packages depends on the course requirement and duration of the course being taught. The software chosen to create the models for this course was ProModel.

The determination that students would not be asked to create models from scratch was based on the fact that model creation can be a very time consuming process and, whereas the basic theoretical makeup of creating a model is the same from one software package to the next, the fine details of using the various software packages can differ greatly. Therefore, the focus of the course remains to be facility layout and design with appropriate assignments to allow students to further visualize various facility layout concepts and conceptualized important soft skills such as "selling" their ideas to management. Ultimately five simulation assignments were developed for the course. These five assignments focus on the main topics that faculty had found to be important during their real life experiences with simulation modeling. The objectives of each assignment are as follows:

Objectives for Assignments

Assignment \#1:

- Identify components required to create a basic process simulation model.

- Implement graphics to appropriately visualize process changes.

Assignment \#2:

- Test what-if scenarios for increasing throughput of process flow.

Assignment \#3:

- Collect and validate existing data in a simulation model.

- Develop and present appropriate alternative solutions.

Assignment \#4:

- Analyze simulation output results.

Assignment \#5:

- Interpret results of business process improvements.

During class, students are instructed on the learning objectives that are covered in each assignment. In the first assignment (see appendix B), the objective is to identify the different components that are required to build the model. During this class students are introduced to the various components required to build a model. This is accomplished by reviewing a basic code that was created as a result of building a model. Figure 1 shows a portion of the code output that is discussed with the students. As a second part to this first assignment, students are introduced to the importance of graphics in process simulation models. Faculty have experienced first-hand that appropriate graphics are vital to gaining management approval for implementation of a proposed project. As students learn the programming aspect of the simulation package, a special emphasis is placed on the simulation model's graphics. In many cases, the intended audience does not have the technical background associated with the model being presented. A visual model of a project will not get management support if they cannot correlate the model to the organization's current processes. Figures 2 and 3 are examples presented to students of simplistic graphics that can be used to aid in the visualization of a process. Figure 2 shows the 
layout of a process within a machining cell and includes simple drag and drop machine icons that are available in most simulation packages. Figure 3 shows the same layout with improved graphics which highlight the various processing stages as the product flows through the cell.

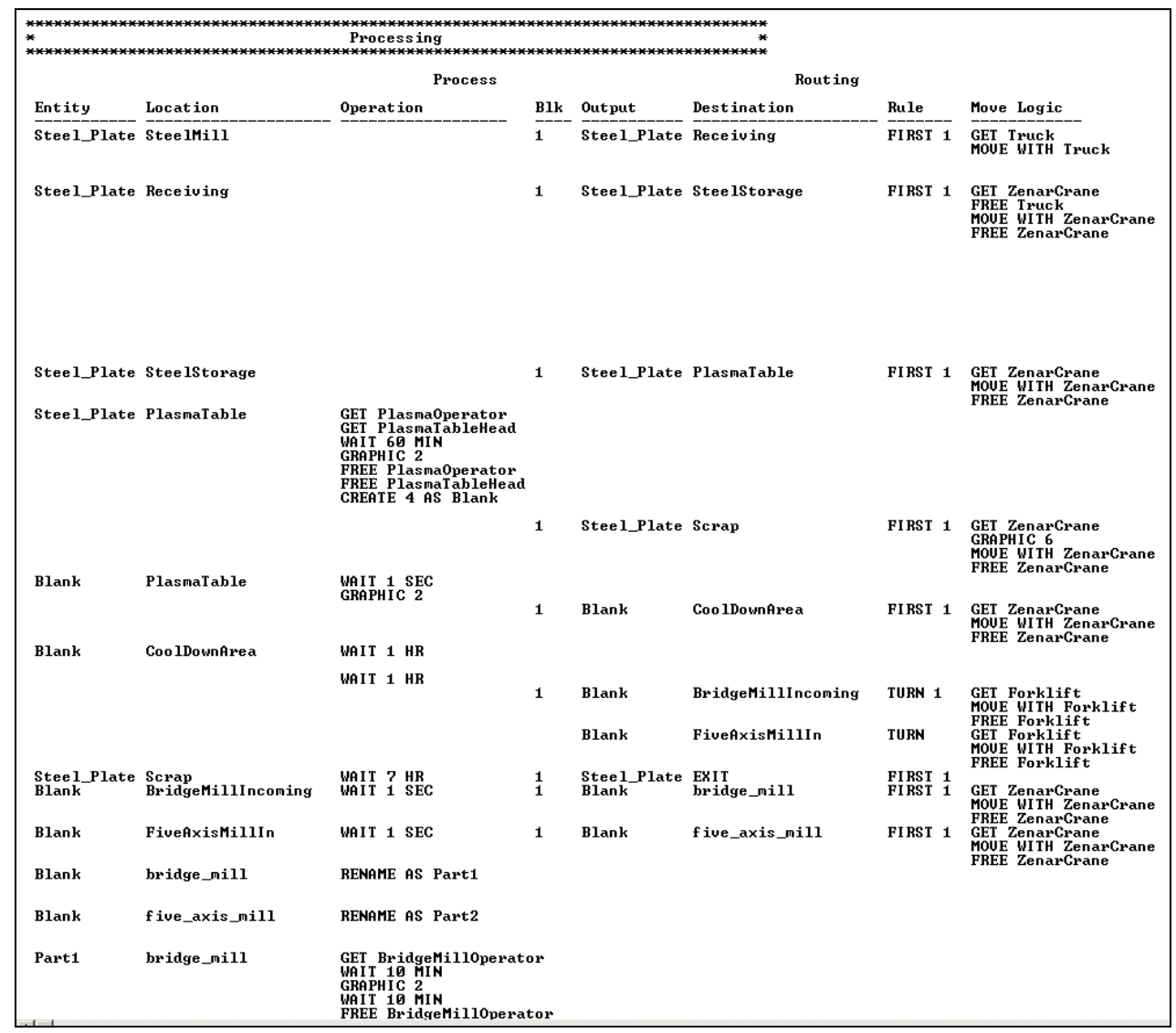

Figure 1

Programming Code Resulting from Simulation Model Created Using ProModel. 


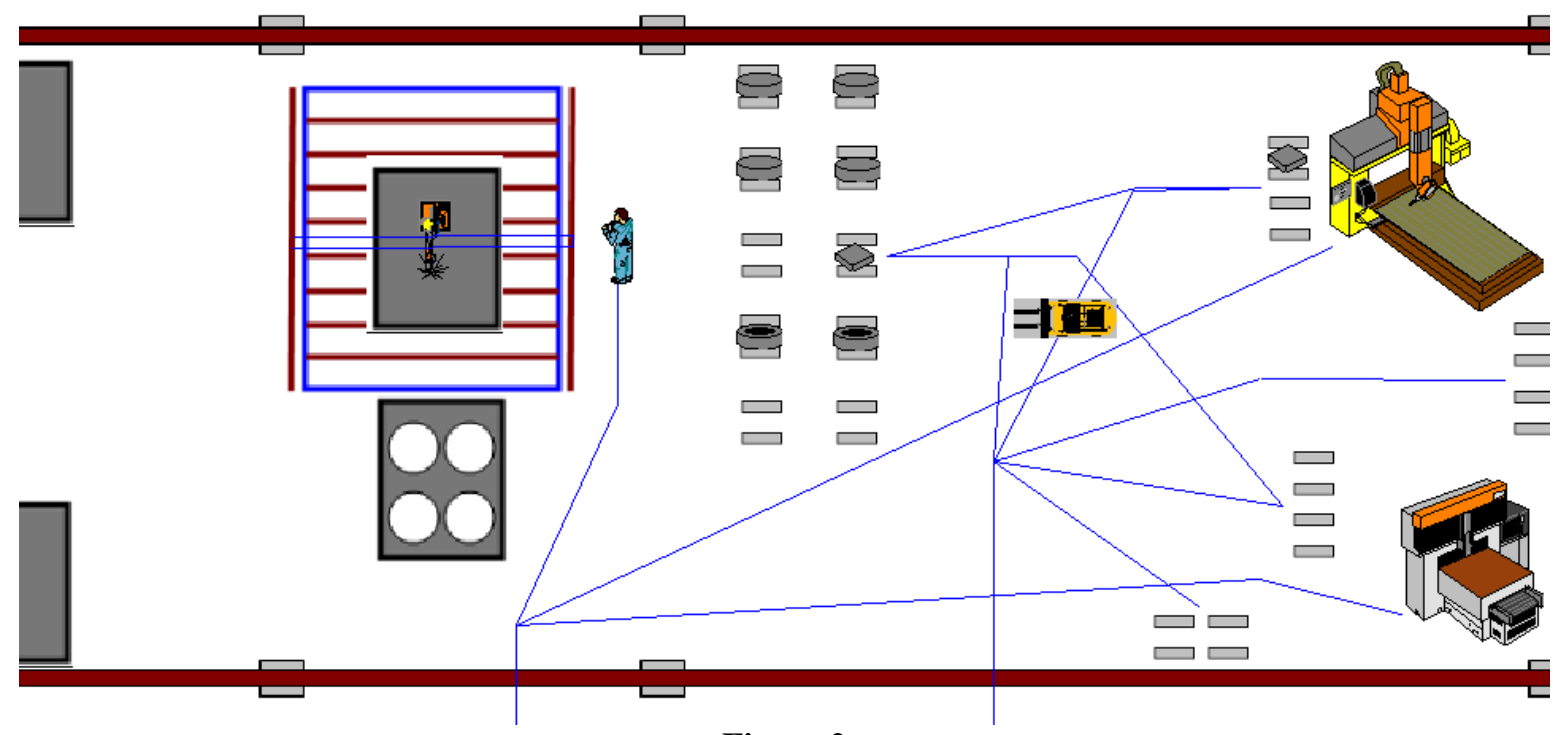

Figure 2

Sample of Class Assignment Using ProModel Graphics Library

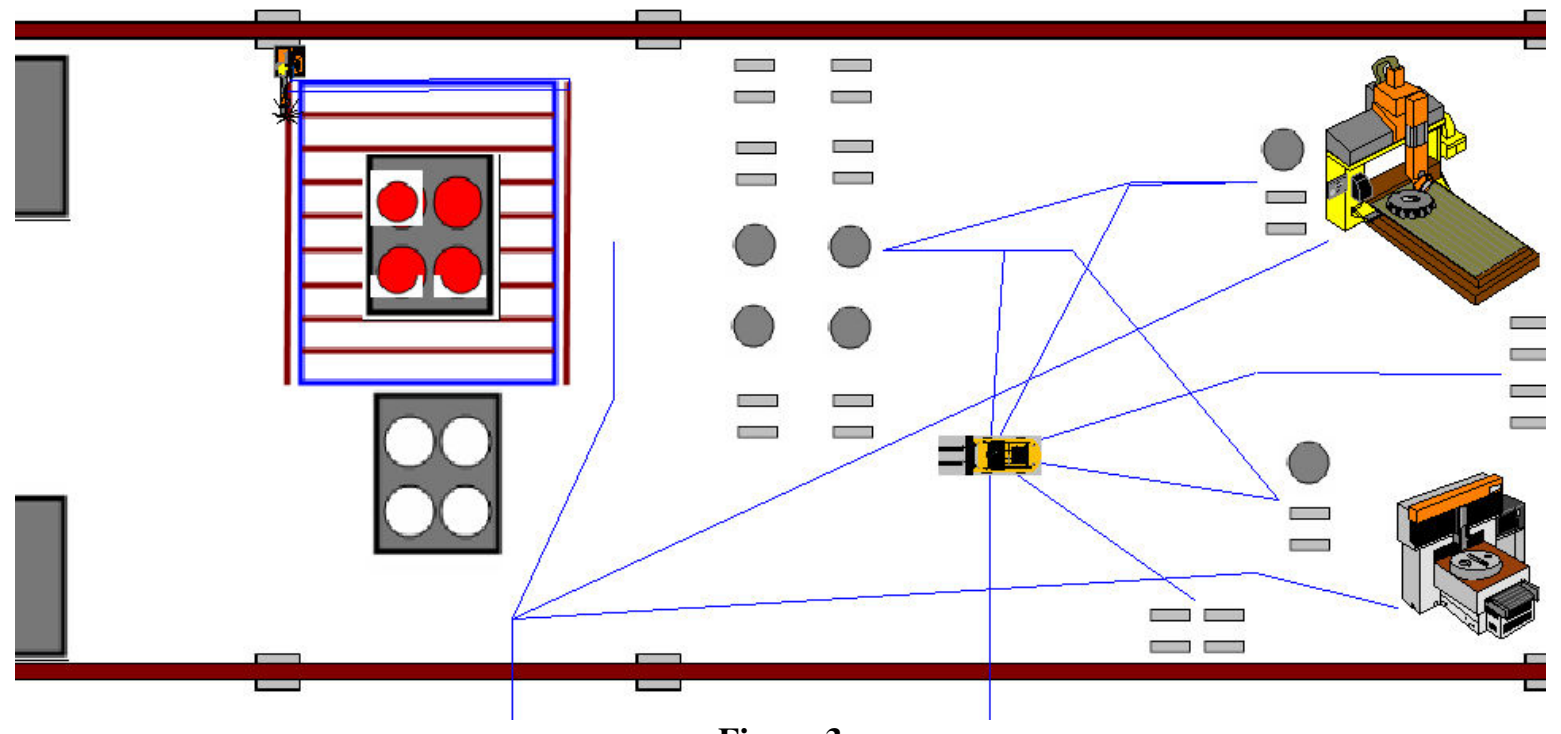

Figure 3

Sample of Class Assignment Using Modified Graphics Library

In the second assignment, the objective is to test what-if scenarios for increasing throughput of process flow. As an example, a model was presented to students in which they will be a prospective franchisee for a fast food restaurant chain. Different cash register line layouts, similar to those found in many of the larger fast food chain restaurants, are presented as options. The students are given some options as to how many registers they want, space for customers to wait for their orders, and how many customers can be in queue before cashiers help fill orders for those customers who are waiting. 
The remaining three assignments show students how to analyze the model's statistics. In addition to a visual representation of the project, management will want additional data that backs up the proposed layout or design. In addition, the validity of the information that was collected, analyzed, and used to generate the design and layout will be tested through the simulated model. For example, models can be developed to test the results from the Machine Requirements Analysis. As equipment suppliers are identified, their equipment specifications can be added to a work cell to test the equipment's effect on the cell's production figures and takt time. Models can be created to verify the utilization of the proposed resources such as material handling equipment and manpower. During brainstorming sessions, models can be easily modified to test different scenarios. The effect of the change in the model will immediately be seen through the simulation and the analysis of the statistics that are generated.

The basis of this IET 310 course is teaching traditional facility layout techniques. Simulation is now used as an aid in teaching these traditional techniques. Since the faculty have determined that the focus of simulation within this undergraduate course should be on learning how to use process simulation models in general to solve problems, less focus was placed on actual model creation. The above described five assignments address this focus.

\section{Lessons Learned}

Incorporating simulation into a traditional facilities design and layout undergraduate course has proven to have some constraints. Although programming simulation models is fairly easy, it is very time consuming. The main constraint that was faced was finding adequate instructional time to incorporate the simulation lessons in conjunction with the traditional facility design concepts. The existing course structure did not provide sufficient instructional and lab time for students to learn how to program, run and analyze the simulation models. In order to remedy this issue it was determined that the most time consuming component was actually associated with the least important skill. Whereas programming the model is important, the specifics of various software packages will differ. Therefore, students were given some theoretical overview of the program as shown in figure 1 above, but were then asked to concentrate more heavily on the analysis of various senarios as the main focus of their simulation assignments. This places the general emphasis on problem solving and less on programming which may have to be relearned throughout a student's career depending on the simulation software package available to them at the time.

Another issue that presented itself was the issue of prerequisites and to what degree preexisting skills must be present in order for a student to be successful at simulation. Typically, traditional facilities design and layout courses already require the use of a drafting software package such as AutoCAD. PUC's IET program requires that students only take one semester of drafting and AutoCAD prior to taking IET 310. Since students may not use AutoCAD on a daily basis, by the time they take the facilities layout course three semesters later, their skills have generally deteriorated. With the incorporation of simulation, AutoCAD has become an additional liability to students who wish to incorporate higher level graphics into their simulation assignments.

It is expected that additional lessons will also be highlighted as student assessments and feedback are collected and analyzed regarding the addition of simulation exercises to this traditional 
course. The first time that these new assignments have been integrated into the IET 310 course is during the Spring 2009 semester. As the information regarding assessment of the intended course learning objectives and other student feedback become available, the course and/or assignments will be further adjusted to aid student's use of modern problem solving tools that was the initial intent of the addition of the simulation exercises.

\section{Conclusion and Future Potential}

Incorporating process simulation exercises into the IET 310 Plant Layout and Material Handling course at PUC has allowed students the opportunity to work with a commercial simulation package (ProModel) in order to prepare for real life problem solving for process improvement. This exposure will translate to a multitude of industries. At the conclusion of the course, students will have been exposed to examples of simulation models, their use as problem solving tools, and additional opportunities to use simulation in their respective careers. A more in depth course that walks students through the whole process of developing a simulation model is needed to meet internal demands that are being generated as a result of student projects. For this reason, the IET faculty at PUC intend to develop a follow-on course, however it has yet to be determined if this course should be developed at the undergraduate or graduate level.

\section{Bibliography}

1. Stephens, M. P. (1997). "Computer simulation in the workplace and technology classes" The Journal of Technology Studies, 23 (1), 7-13.

2. Chan, F.T.S. and Chan, H.K. (2007) 'A simulation approach for managing manufacturing processes and inbound logistics: a case study', Int. J. Business and Systems Research, Vol. 1, No. 1, pp.115-134.

3. Evon M. O. Abu-Taieh and Asim Abdel Rahman El Sheikh, "Commercial Simulation Packages: A Comparative Study", International Journal of Simulation, Vol 8, No 2, pp.66-76.

4. Andre Baumgart, Anja Zoeller, Christof Denz, Hans-Joachim Bender, Armin Heinzl, Essameddin Badreddin, "Using Computer Simulation in Operating Room Management: Impacts on Process Engineering and Performance", Proceedings of the 40th Hawaii International Conference on System Sciences - 2007, pp.131b.

5. Yvonne Lejtman, Ebrhim Shayan, Romesh Nagarajah, "Design of a suitable production management system for a manufacturing company", Computers \& Industrial Engineering, 42(2002), pp.169-174.

6. Andrew Potter, Biao Yang, Chandra Lalwani, "A simulation study of dispatch bay performance in the steel processing industry", European Journal of Operational Research, Vol 179, Issue 2, pp.567-578.

7. Simone Appelt, Rajan Batta, Li Lin, Colin Drury, "Simulation of passenger check-in at a medium-sized US Airport", Proceedings of the 2007 Winter Simulation Conference, S. G. Henderson, B. Biller, M.-H. Hsieh, J. Shortle, J. D. Tew, and R. R. Barton, (eds.) pp.1252-1260.

8. Savsar, M. \& Cogun, C. (1996). Performance evaluation of a flexible manufacturing cell (FMC) by computer simulation, modeling measurement, \& control. 62(2), 31-44

9. Savsar, M. (1990). Flexible facility layout by simulation, computer and industrial engineering. 20(1), 155165.

10. Williams, D. L., Finke, D. A., Medeiros, D. J.,\& Traband, M. T. Discrete simulation development for a proposed shipyard steel processing facility, in proceedings of the 2001 winter simulation conference, ed. Peter, B. A., Smith, J. S., Medeiros, D. J., \& Rohrer, 882-887. Piscataway, New Jersey: Institute of Electrical and Electronics Engineers.

11. West, A.A., Rahimifard, R. H., \& Williams, D. J. (2000). The development of a visual interactive simulation of packaging flow lines, International Journal of Production Research 38(18): 4714-4741.

12. Kibira, D. \& McLean, C.Virtual Reality Simulation of Mechanical Assembly Production Line, in proceedings of the 2002 winter simulation conference, eds. Yucesan, E., Chen, C. H., Snowdon, J. L., \& Charnes, J. M. 1130-1137.Gaithersburg, MD: National Institute of Standards and Technology. 
13. Law, A. M., \& McComas, M. G. "Simulation of manufacturing systems, in proceedings of the 1997 winter simulation conference, ed. Nelson, B. L., Andradottir, S., Healy, K. J., \& Withers, D. H., 86-89. Tucson, AZ.

14. José A. Sepúlveda, William J. Thompson, Felipe F. Baesler and María I. Alvarez, The Use of Simulation for Process Improvement in a Cancer Treatment Center, Proceedings of the 1999 Winter Simulation Conference, P. A. Farrington, H. B. Nembhard, D. T. Sturrock, \& G. W. Evans (eds.), pp. 1541-1548.

15. Gokhale, A. A. (1996). "Effectiveness of computer simulation for enhancing higher order thinking." Journal of Industrial Teacher Education, 33(4), 36-46.

16. Accreditation Board for Engineering and Technology; http://www.abet.org/accredittac.asp; retrieved 1-3009. 
Appendix A

\begin{tabular}{|l|c|}
\hline \multicolumn{1}{|c|}{ ABET Accredited Industrial Engineering Technology Programs } & $\begin{array}{c}\text { Internet Mention } \\
\text { of Process } \\
\text { Simulation }\end{array}$ \\
\hline University of Dayton & Yes \\
\hline Gaston College & No \\
\hline Indiana University-Purdue University Fort Wayne & Yes \\
\hline State University of New York Institute of Technology at Utica/Rome & Yes \\
\hline North Western State University of Louisiana & No \\
\hline Pellissippi State Technical Community College & No \\
\hline Purdue University North Central & Yes \\
\hline Sinclair Community College & No \\
\hline South Carolina State University & Yes \\
\hline University of Southern Mississippi & Yes \\
\hline Southern Polytechnic State University & Yes \\
\hline
\end{tabular}

\section{ABET Accredited Manufacturing Engineering Technology Programs}

Internet Mention

of Process

Simulation

Arizona State University - East

Ball State University

Bradley University

Brigham Young University

Butler Community College

California State University, Long Beach

Central Connecticut State University

Chattanooga State Technical Community College

University of Cincinnati, OMI College of Applied Science

University of Dayton

East Tennessee State University

Essex County College

Lake Superior State University

The University of Memphis

Midwestern State University

Minnesota State University, Mankato

Naugatuck Valley Community College

New Hampshire Technical Institute

University of North Texas

Northern Illinois University

Northern Kentucky University

Oregon Institute of Technology

Pellissippi State Technical Community College

Pittsburg State University

Purdue University at West Lafayette

Rochester Institute of Technology

South Dakota State University

Southwestern Oklahoma State University

State University of New York, College of Technology at Farmingdale

Texas A \& M University

Three Rivers Community College

Weber State University

Western Michigan University

Western Washington University

\begin{tabular}{|l|}
\hline Yes \\
\hline Yes \\
\hline No \\
\hline No \\
\hline No \\
\hline No \\
\hline No \\
No \\
\hline Yes \\
\hline No \\
\hline No \\
\hline No \\
\hline Yes \\
\hline No \\
\hline Yes \\
\hline No \\
\hline No \\
\hline No \\
\hline No \\
\hline Yes \\
\hline No \\
\hline Yes \\
\hline No \\
\hline Yes \\
\hline Yes \\
\hline No \\
\hline No \\
\hline No \\
\hline No \\
\hline Yes \\
\hline No \\
\hline Yes \\
\hline Yes \\
\hline Yes \\
\hline
\end{tabular}




\section{Appendix B}

\section{Simulation Assignment \#1}

\section{Graphics and Visualization}

Objective

- Identify components required to create a basic process simulation model.

- Implement graphics to appropriately visualize process changes.

Simulation Model Background Information

C \& S Machining Co. is a small family owned business based out of Elgin, IL. Recently, the owners have acquired a simulation software package (ProModel) to make improvements to their operations. Currently, their operations consist of receiving 4" thick plates from the steel mills and storing them in their steel warehouse, plasma cut the plates into rough shapes, and machining the rough shapes into one of two parts that they are currently supplying to a major construction equipment manufacturer. A simulation model of C \& S Machining Co.'s operations has been created but needs a few changes before it is presented to management.

\section{$\underline{\text { Assignment }}$}

\section{Part 1:}

Change the model programming so that the Resources listed below return to the "Break Area" or N1 when ever they are off shift, on break, or idle. Also, check the Return Home If Idle box.

1. PlasmaOperator

2. BridgeMillOperator

3. FiveAxisMillOperator

Answer the following questions:

1. What did you notice about the machine operators before the programming was changed? After the programming was changed?

2. Which version of the model would you present to management, before or after the programming change? Explain why?

Part 2:

After the 4" thick plates are cut into rough shapes in the Plasma Table, they are moved with the crane to the Cool Down Area where they must sit for 2 hours before they can be machined. Change the model programming so that the Entity of the rough shapes or Blank changes color after 1 hour of waiting and after 2 hours of waiting in the Cool Down Area.

\section{CURRENT}

\begin{tabular}{|c|c|c|c|}
\hline \multicolumn{3}{|c|}{ Processing } \\
\hline Program Line & Entity & Location & Operation \\
\hline 6 & Blank & CoolDownArea & WAIT 1 HR \\
& & & \\
\hline
\end{tabular}

PROGRAMMING CHANGE

$\hookrightarrow$\begin{tabular}{|c|c|c|c|}
\hline \multicolumn{4}{|c|}{ Processing } \\
\hline Program Line & Entity & Location & Operation \\
\hline 6 & Blank & CoolDownArea & $\begin{array}{l}\text { WAIT 1 HR } \\
\text { GRAPHIC 3 } \\
\text { WAIT 1 HR } \\
\text { GRAPHIC 1 }\end{array}$ \\
\hline
\end{tabular}

Answer the following questions:

1. What color were the rough shapes or Blank before the programming was changed? Why do you think the rough shapes or blanks were this color? What color were the rough shapes or Blank after the programming was changed and they had waited in the Cool Down Area for 1 hour? After 2 hours?

2. Observed the Plasma Table during overnight or off shift. What did you notice about the color of the rough shapes or Blanks that were left at the Plasma Table? What happened to their color when they were moved to the Cool Down Area? Explain your observations?

3. Do you believe that graphics can be an additional tool for understanding processes and solving problems? If so explain why and give an example? 